OPEN ACCESS

Edited by:

Carmen Fenoll,

University of Castilla-La Mancha,

Spain

Reviewed by:

Jens Staal,

Ghent University, Belgium

Jungen Kang,

Beijing Vegetable Research Center,

China

*Correspondence:

Yumei Liu

liuyumei@caas.cn

Specialty section: This article was submitted to Plant Biotic Interactions, a section of the journal

Frontiers in Plant Science

Received: 05 October 2016 Accepted: 05 December 2016 Published: 23 December 2016

Citation:

Zhang X, Liu Y, Fang Z, Li Z, Yang L, Zhuang M, Zhang $Y$ and LV H (2016) Comparative Transcriptome Analysis between Broccoli (Brassica oleracea var. italica) and Wild Cabbage (Brassica macrocarpa Guss.) in Response to Plasmodiophora brassicae during Different Infection Stages. Front. Plant Sci. 7:1929. doi: 10.3389/fpls.2016.01929

\section{Comparative Transcriptome Analysis between Broccoli (Brassica oleracea var. italica) and Wild Cabbage (Brassica macrocarpa Guss.) in Response to Plasmodiophora brassicae during Different Infection Stages}

Xiaoli Zhang, Yumei Liu*, Zhiyuan Fang, Zhansheng Li, Limei Yang, Mu Zhuang, Yangyong Zhang and Honghao Lv

Group of Cabbage and Broccoli Breeding, Institute of Vegetables and Flowers - Chinese Academy of Agricultural Sciences, Beijing, China

Clubroot, one of the most devastating diseases to the Brassicaceae family, is caused by the obligate biotrophic pathogen Plasmodiophora brassicae. However, studies of the molecular basis of disease resistance are still poor especially in quantitative resistance. In the present paper, two previously identified genotypes, a clubroot-resistant genotype (wild cabbage, B2013) and a clubroot-susceptible genotype (broccoli, 90196) were inoculated by P. brassicae for 0 (T0), 7 (T7), and 14 (T14) day after inoculation (DAI). Gene expression pattern analysis suggested that response changes in transcript level of two genotypes under $P$. brassicae infection were mainly activated at the primary stage (T7). Based on the results of DEGs functional enrichments from two infection stages, genes associated with cell wall biosynthesis, glucosinolate biosynthesis, and plant hormone signal transduction showed down-regulated at T14 compared to T7, indicating that defense responses to $P$. brassicae were induced earlier, and related pathways were repressed at T14. In addition, the genes related to NBS-LRR proteins, SA signal transduction, cell wall and phytoalexins biosynthesis, chitinase, $\mathrm{Ca}^{2+}$ signals and $\mathrm{RBOH}$ proteins were mainly up-regulated in B2013 by comparing those of 90196 , indicating the pathways of response defense to clubroot were activated in the resistant genotype. This is the first report about comparative transcriptome analysis for broccoli and its wild relative during the different stages of $P$. brassicae infection and the results should be useful for molecular assisted screening and breeding of clubroot-resistant genotypes.

Keywords: clubroot, Plasmodiophora brassicae, broccoli, wild cabbage, RNA sequencing 


\section{INTRODUCTION}

Clubroot disease, caused by the obligate biotrophic pathogen Plasmodiophora brassicae, is one of the most devastating diseases to the Brassicaceae family (Ludwig-Müller et al., 2009). For many years, this soil-borne disease has caused declines in both the quality and yields of cruciferous crops worldwide (Dixon, 2009). The life cycle of $P$. brassicae consists of two distinct stages: the primary stage and the secondary stage. During the primary stage (root-hair infection stage), motile zoospores attach to the surface of root hairs, encyst, and release an amoeboid unit into the cell to form primary plasmodia. The plasmodia undergo a series of cell divisions to form multinucleate secondary plasmodia, which induce cell hypertrophy and cell hyperplasia in the tissues of the cortex and stele, leading to the development of galls. Eventually, the secondary plasmodia cleave into numerous resting spores that are released into the soil when the galls disintegrate (Rolfe et al., 2016). These P. brassicae spores can survive in the soil for up to 20 years, making the disease difficult to control in the field once soil is contaminated (Kageyama and Asano, 2009). Thus, studies on strategies and technologies for reducing the risk of clubroot contamination of cruciferous plants, especially cultivated crops, are urgently needed.

Screening and breeding clubroot-resistant (CR) cultivars is an effective and economical approach for reducing the use of chemical fungicides while minimizing crop losses. Some CR cultivars of cruciferous crops such as Chinese cabbage, cabbage, cauliflower, and oilseed rape are available for commercial production, but resistance may be overcome by rapidly evolving pathogen populations after large-scale application (Diederichsen et al., 2009). Therefore, a better understanding of the molecular mechanisms of clubroot disease development and host-P. brassicae interactions may provide strategies for improving plant tolerance of $P$. brassicae infections and establishing a theoretical basis for breeding resistant varieties.

Arabidopsis thaliana can also be infected by $P$. brassicae and therefore serves as a useful model host for studying the disease (Koch et al., 1991; Mithen and Magrath, 1992; Ludwig-Müller et al., 2009). Previous studies have advanced our understanding of the events leading to clubroot formation using various methods, including resistance screening (Fuchs and Sacristan, 1996), mutant analysis (Siemens et al., 2002, 2008; Alix et al., 2007), and genetic analysis of resistance (Jubault et al., 2008b; Gravot et al., 2011). In the past decade, several “-omics" approaches have been employed to elucidate the dynamic changes in protein composition and gene expression related to metabolic pathways during clubroot disease and more complex signaling pathways that are activated in response to $P$. brassicae infection. Deckers (2006), who focused on changes in the protein compositions in A. thaliana, showed that proteins involved in metabolism, cell defense, cell differentiation, and detoxification were differentially regulated during the initial infection stage. Several studies have addressed the roles of genes related to metabolism, hormone signaling, and defense responses based on transcriptome analyses in specific developmental stages (Siemens et al., 2006; Jubault et al., 2008a; Ludwig-Müller et al., 2009; Agarwal et al., 2011; Schuller et al., 2014).

It is also clear that there are differences in the resistance response between A. thaliana and Brassica species (Kobelt et al., 2000). Thus, previous studies have focused on understanding the mechanisms underlying clubroot disease resistance in Brassica species, including Brassica rapa and Brassica napus. Chu et al. (2014) identified differentially expressed genes (DEGs) involved in the signaling metabolism of jasmonate and ethylene, defensive deposition of callose and the biosynthesis of indole-containing compounds, which were all significantly upregulated in clubroot-resistant plants compared with susceptible cultivars. More recently, Chen et al. (2016) confirmed that genes associated with PAMPs, calcium ion influx, hormone signaling, PR, transcription factors, and cell-wall modification played important roles in host- $P$. brassicae interactions during the early stages of infection by $P$. brassicae, based on transcriptome analysis of B. rapa. Xu et al. (2016) provided evidence of the involvement of IAA pathway-related genes during the root-hair infection stage in the roots and leaves of B. napus soon after P. brassicae inoculation based on qRT-PCR analysis.

Brassica oleracea is one of the most important worldwide leafy vegetables. Clubroot results in severe losses of yield and quality in B. oleracea as well as in other Brassica crops. However, there is little information on the molecular mechanisms of clubroot resistance in B. oleracea and its wild relatives obtained through transcriptome analysis, especially on studies that compare responses to $P$. brassicae infection between susceptible and resistant plant lines. Besides, previous studies have showed that clubroot resistance in $B$. oleracea is quantitative under polygenic control (Tomita et al., 2013). Up until now, only a few studies, done on Arabidopsis, have focused on the mechanisms controlling quantitative resistance (Jubault et al., 2013). Hence, for molecular mechanisms of resistance in B. oleracea, it is very necessary and urgent to get a comprehensive understanding through transcriptome analysis.

Here, comparative transcriptome analysis was employed for the roots of two genotypes (broccoli and its wild relative) to clarify two major issues: (1) what are the differences in the transcriptional response to $P$. brassicae infection associated with different stages; and (2) what is the genetic basis for the differences in resistance to clubroot between the two genotypes? Through the bioinformatics analysis, we believe that our results would provide new insight into the molecular mechanisms that impart high resistance to clubroot.

\section{MATERIALS AND METHODS}

\section{Plant Material and Pathogen Isolate}

On the basis of a previous study (Zhang, 2014), two identified genotypes-a clubroot-susceptible inbred broccoli line (90196, B. oleracea var. italica) and a clubroot-resistant wild cabbage line (B2013, Brassica macrocarpa Guss.) - were used in the present study. The wild type was able to intercross and produce fertile progeny with cultivated B. oleracea crops, including 90196. 
The root galls used in this study were collected from clubrootinfested field plots of Chinese cabbage in Tong'hai, Yunnan, China. The strain of the resting spores isolated from the galls was identified as pathotype 4 (Zhang, 2014), according to the differential classification of Williams (1966). Preparation of the resting spore suspension was performed as described by Luo et al. (2014), and the spore suspension was diluted with sterile water to $3 \times 10^{8}$ spores $/ \mathrm{mL}$ and stored at $4^{\circ} \mathrm{C}$.

\section{P. brassicae Inoculation}

To facilitate observation of the infection stage, infection of $P$. brassicae was performed in an improved culture solution according to Luo et al. (2014), with slight modification. Plant seeds were germinated on wet filter paper for 6 days $\left(25^{\circ} \mathrm{C}, 16-\mathrm{h}\right.$ photoperiod). Then, $15-\mathrm{ml}$ centrifuge tubes were wrapped in silver paper, and half-strength Hoagland's nutrient solution (Hoagland and Arnon, 1950), which was used as the culture solution, was added to the tubes, after which the $\mathrm{pH}$ was adjusted to 6.0. One seedling was placed at top of each tube, held in place with a thin sponge. The plants were inoculated after 3 days of growth in solution by pipetting $1 \mathrm{~mL}$ of spore suspension $\left(3 \times 10^{8}\right.$ spores $\left./ \mathrm{mL}\right)$ into the tube; control plants were inoculated with an equivalent amount of sterile water. The seedlings were maintained for the duration of the experiment in an intelligent artificial climate chamber (RXZ, Jiangnan Instrument, Ningbo, China; 16 -h light at $25^{\circ} \mathrm{C}$ day, 8 -h dark at $20^{\circ} \mathrm{C}, 75 \%$ relative humidity). Fresh nutrient solution was added to the tubes as required.

\section{Microscopic Investigation and Tissue Sampling}

To determine the timing of primary and secondary infection in the two genotypes, the infection processes of $P$. brassicae in the roots were magnified using an optical microscope (Olympus CX31, Japan) and imaged with a camera (Nikon 550D, Japan) every day after inoculation until the secondary infection was established. The spores were removed from the roots by gentle, thorough washing with sterile water. The roots were cut into 1-cm sections, which were then observed under a microscope after being fixed in formyl acid (FAA) and stained with modified carbol fuchsin. The stained root segments were mounted onto glass slides with a coverslip. At each time point, five individual plants were examined and three roots were observed from each plant.

Based on the observed infection stages, primary and secondary infection was found to occur at seven and 14 days after inoculation (DAI), respectively. Thus, the roots of 90196 and B2013 plants were sampled at 0 (T0), 7 (T7), and 14 (T14) DAI for the analysis of DEGs at different stages of infection. The roots of 10 (two biological replications, five plants for each replicate) plants were sampled and pooled for RNA extraction at each time point, for RNA sequencing. The roots were washed with sterile water, then immediately frozen in liquid nitrogen and stored at $-80^{\circ} \mathrm{C}$ until use. To verify successful infection, plants were transplanted to nutrition pots $(9 \mathrm{~cm} \times 9 \mathrm{~cm})$ containing a mixture of vermiculite: compost $(1: 2, \mathrm{v} / \mathrm{v})$ after inoculation for 20 days in culture solution. The plants were gently removed from the soil at 42 DAI. The severity of symptoms was recorded using the scale previously described for B. oleracea (ManzanaresDauleux et al., 2000), and the disease index (DI) was calculated as described by Manzanares-Dauleux et al. (2000). A line showing a DI value higher than 25 was considered to be susceptible to clubroot. The experiment was repeated three times.

\section{RNA Extraction, Sequencing, and De novo Assembly}

Total RNA was extracted from a mixture of the root tissues of five individual plants as one replication for each of T0, T7, and T14 using the RN38-EASY SPIN Plus Plant Kit (BioTeke, Beijing, China), following the manufacturer's instructions. The integrity of the RNA was verified through RNase-free agarose gel electrophoresis, and the concentration was measured using a 2100 Bioanalyzer (Agilent Technologies, Santa Clara, CA, USA). High-quality RNA from each replication of each treatment was pooled in equal quantities to generate one mixed sample for RNA sequencing. A cDNA library was constructed for each of the 12 mixed RNA samples and sequenced on the Illumina HiSeq $4000^{\mathrm{TM}}$ platform (Illumina, Inc., San Diego, CA, USA), which was conducted by the Allwegene Technology Company in Beijing, China. Before assembly, adapter sequences were removed from the raw reads. Low-quality reads ( $>50 \%$ bases with quality scores $\leq 5)$ and unknown bases ( $>10 \% \mathrm{~N}$ bases) were removed from each dataset to obtain more reliable results. The high-quality clean reads from all 12 samples were merged and assembled via the Trinity method (Grabherr et al., 2011) to construct unique consensus sequences for use as reference sequences.

\section{Analysis of Differential Gene Expression and Gene Annotation}

The sequencing reads for each sample were remapped to the reference sequences using RSEM software (Li et al., 2011). Gene expression levels were measured using the FPKM (Fragments Per Kilobase of transcript per Million fragments) method (Trapnell et al., 2010) based on the number of uniquely mapped reads. For genes with more than one alternative transcript, the longest transcript was selected to calculate the FPKM. The DESeq package (ver. 2.1.0) (Anders and Huber, 2010) was employed to detect DEGs between two samples. The false discovery rate (FDR) was applied to correct the $p$-value threshold in multiple tests (Benjamini and Hochberg, 1995). An FDR-adjusted $p$-value ( $q$-value $) \leq 0.05$ and a $\mid \log 2$ FoldChange $\mid>1$ were used as the threshold for identifying significant differences in gene expression in this study.

All expressed genes were functionally annotated using five databases, including the NCBI non-redundant protein $(\mathrm{Nr})$, Eukaryotic Ortholog Groups $\left(\mathrm{KOG}^{1}\right)$, Protein family $\left(\mathrm{Pfam}^{2}\right)$, Swiss-Prot ${ }^{3}$, and Kyoto Encyclopedia of Genes and Genomes

\footnotetext{
${ }^{1}$ http://www.ncbi.nlm.nih.gov/COG/

${ }^{2}$ http://pfam.sanger.ac.uk/

${ }^{3}$ http://www.ebi.ac.uk/uniprot/
} 
$\left(\mathrm{KEGG}^{4}\right)$ databases, employing BlastX (v. 2.2.28+) with an E-value of less than 1e-5. Gene Ontology $\left(\mathrm{GO}^{5}\right)$ annotations were analyzed using Blast2GO (v.2.5) (Conesa et al., 2005). For a gene that was matched to multiple protein sequences, the protein with the highest similarity score was considered the optimal annotation. To infer the transcriptional changes over time in the two genotypes under $P$. brassicae infection, DEGs at 7 and 14 DAI were identified by comparing the expression levels at T7 with those at T0 and the level at T14 with those at T7 in B2013 and 90196, respectively. For convenience, DEGs showing higher expression levels at T7 than at T0 and those exhibiting higher expression at T14 than at T7 were designated "up-regulated," whereas those that displayed lower expression were designated "downregulated."

\section{Gene Expression Validation}

Eight genes with different expression levels, as revealed via RNA sequencing, were randomly selected for validation using quantitative real-time RT-PCR (qRT-PCR). The gene-specific primers designed according to the gene sequences using Primer Premier $5^{6}$ were listed in Supplementary Table S1. Three technical replicates were performed for each gene. First-strand cDNA was synthesized using the PrimeScript RT reagent Kit (TAKARA BIO, Inc., Shiga, Japan). The relative transcription level of each gene was estimated in terms of threshold cycles using the $2^{-\Delta \Delta C T}$ method (Livak and Schmittgen, 2001), and broccoli $\beta$-actin was employed as an internal control (Gómez-Lobato et al., 2012). qRT-PCR was carried out using SYBR Premix Ex TaqII (Tli RNaseH Plus; TAKARA BIO, Inc., Shiga, Japan) on an ABI Prism ${ }^{\circledR}$ 7900HT (Applied Biosystems, Carlsbad, CA, USA) according to the manufacturer's instructions.

\section{RESULTS}

\section{Disease Severity in the Two Genotypes and Infection Processes}

The disease severity of the two genotypes was assessed at 42 DAI with P. brassicae. B2013 plants infected with pathotype 4 of $P$. brassicae showed only tiny clubs, with a mean DI of 10.71 at 42 DAI, while 90196 was susceptible in response to inoculation with the same $P$. brassicae pathotype, with a mean DI of 94.05, exhibiting a large club that replaced the main and secondary root systems (Table 1; Supplementary Figure S1). The infection process of $P$. brassicae between B2013 and 90196 was monitored after inoculation. At 7 and 14 DAI, microscopic observations revealed that root-hair infection and cortical infection were both present in B2013 and 90196 (Figure 1). For this reason, three time points $(0,7,14 \mathrm{DAI})$ were selected to investigate the differential transcript changes between the two genotypes.

\footnotetext{
${ }^{4} \mathrm{http}: / /$ www.genome.jp/kegg/

${ }^{5} \mathrm{http}: / /$ www.geneontology.org/

${ }^{6} \mathrm{http}: / /$ www.premierbiosoft.com/crm/jsp/com/pbi/crm/clientside/ProductList.jsp
}

TABLE 1 | Evaluation of B2013 and 90196 responses to pathotype 4 of Plasmodiophora Brassicae.

\begin{tabular}{lcc}
\hline Genotype & $\begin{array}{c}\text { Disease } \\
\text { index (DI) }\end{array}$ & $\begin{array}{c}\text { Resistant/ } \\
\text { susceptible }\end{array}$ \\
\hline B2013 & $94.05 \pm 2.06$ & $\mathrm{R}$ \\
90196 & $10.71 \pm 3.57$ & $\mathrm{~S}$ \\
\hline
\end{tabular}

\section{RNA Sequencing and De novo Assembly of the Root Transcriptome of the Two Genotypes}

Approximately 49.53-80.92 million 150-bp paired-end reads were generated from the 12 samples through RNA sequencing (Table 2). The GC content of the sequence data from the 12 libraries ranged from 46.20 to $50.50 \%$, and the Q30\% values (reads with an average quality scores $>30$ ) were all $\sim 90 \%$, indicating that the quality and accuracy of sequencing data were sufficient for further analysis. The percentage of sequenced reads from all libraries remapped to the assembled reference transcripts was $\sim 70 \%$. After sequence trimming, the retained high-quality reads of all samples were merged and de novo assembled into 65,135 unigenes as reference transcripts, and 44,519 of these unigenes were functionally annotated in at least one database with an e-value cutoff of 1e-5. The N50 of the assembled genes was $1490 \mathrm{bp}$, with an average length of $915.5 \mathrm{bp}$ and a maximum length of $14,801 \mathrm{bp}$. The sequencing data has been deposited into NCBI sequence read archive (SRA) under BioProject accession PRJNA345072 (alias: SRP090719).

\section{RNA Sequencing Validation by qRT-PCR}

To validate the results obtained from RNA sequencing, eight genes with different expression levels were randomly selected to perform qRT-PCR. For each gene, the FPKM values of transcriptome data exhibited similar expression trends at all the three time stages comparing with the results of qRT-PCR (Figure 2). It suggested a reliable expression results generated by RNA sequencing.

\section{Gene Expression Pattern Analysis, Clustering, and Functional Enrichment of DEGs}

The DEGs of B2013 and 90196 from different stages were clustered into eight profiles based on gene expression patterns using STEM software. The profiles showed similar patterns in gene expression over time in response to $P$. brassicae between the two genotypes. As shown in Figure 3, most of the DEGs were significantly overrepresented in the profiles exhibiting apparent changes in expression levels at T7 (Profiles 5 and 6, $p<0.05$ ), whereas a small percentage of the DEGs were overrepresented in Profile 7 ( $p<0.05)$, in which gene expression levels increased over the time course of infection. Next, the DEGs belonging to the overrepresented profiles were subjected to GO-term analysis and KEGG classifications (Supplementary Tables S2 and S3). From the GO category of biological process in B2013, genes involved in cytoskeleton metabolic process, cell wall organization 


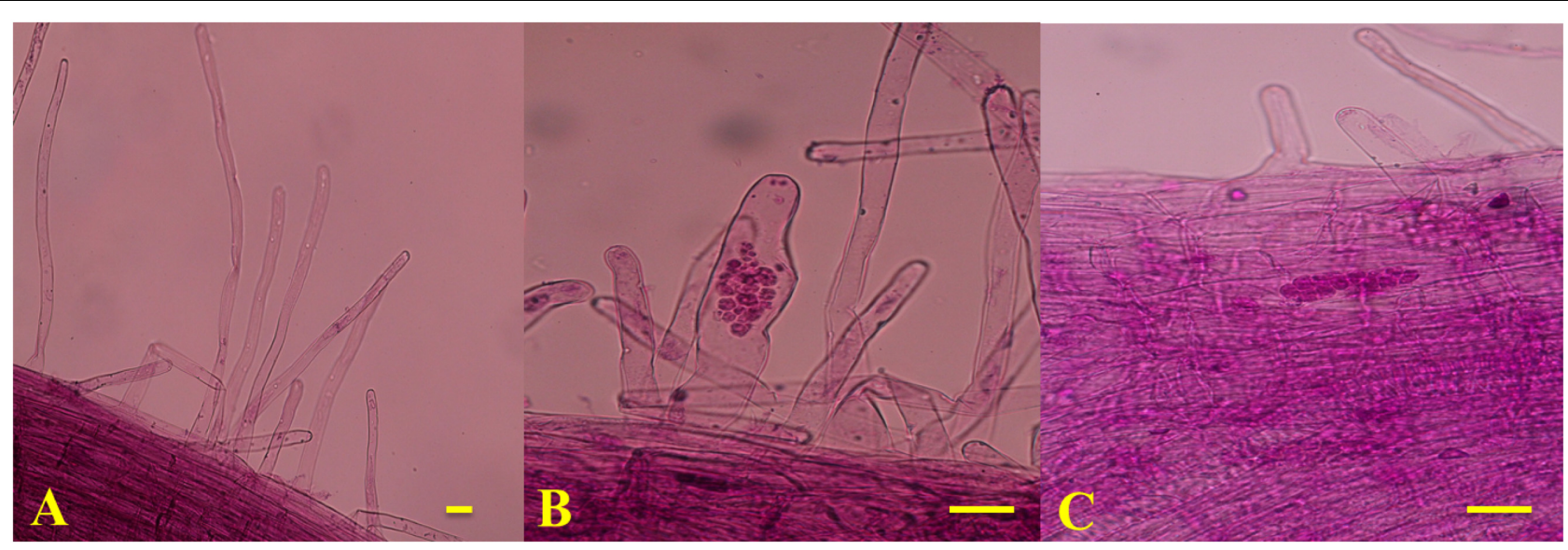

FIGURE 1 | Microscope observation results of T0 (A), T7 (B; the primary infection stage) and (C; the secondary infection stage). Bars $=1 \mu \mathrm{m}$.

TABLE 2 | Sequencing and assembly statistics for the 12 transcriptome data of two genotypes at different stages during $P$. brassicae infection.

\begin{tabular}{|c|c|c|c|c|c|c|c|c|}
\hline \multicolumn{2}{|c|}{ Samples ID } & \multirow{2}{*}{$\begin{array}{c}\begin{array}{c}\text { No. of raw } \\
\text { reads }\left(\times \mathbf{1 0}^{6}\right)\end{array} \\
66.24\end{array}$} & \multirow{2}{*}{$\begin{array}{c}\begin{array}{c}\text { No. of clean } \\
\text { reads }\left(\mathbf{x} \mathbf{1 0}^{6}\right)\end{array} \\
62.77\end{array}$} & \multirow{2}{*}{$\begin{array}{c}\begin{array}{c}\text { No. of base } \\
\text { pairs }\left(\times \mathbf{1 0}^{9}\right)\end{array} \\
9.42\end{array}$} & \multirow{2}{*}{$\begin{array}{c}\begin{array}{c}\text { GC content } \\
(\%)\end{array} \\
48.68\end{array}$} & \multirow{2}{*}{$\begin{array}{c}\text { Q30 (\%) } \\
94.30\end{array}$} & \multirow{2}{*}{$\begin{array}{c}\begin{array}{c}\text { No. of mapped } \\
\text { reads }\left(\times 10^{6}\right)\end{array} \\
44.73\end{array}$} & \multirow{2}{*}{$\begin{array}{c}\text { Mapped } \\
\text { percentage (\%) } \\
71.26\end{array}$} \\
\hline B2013 & 14DAl_1 & & & & & & & \\
\hline & 14DAl_2 & 59.30 & 55.47 & 8.32 & 50.50 & 94.34 & 40.80 & 73.60 \\
\hline & 7DAl_1 & 61.34 & 56.37 & 8.46 & 47.40 & 90.15 & 40.08 & 71.11 \\
\hline & 7DAI_2 & 57.55 & 52.45 & 7.86 & 47.48 & 89.64 & 37.22 & 70.96 \\
\hline & ODAI_1 & 80.92 & 74.59 & 11.18 & 46.87 & 94.46 & 52.41 & 70.27 \\
\hline & ODAI_2 & 55.08 & 50.44 & 7.56 & 46.91 & 94.58 & 35.03 & 69.45 \\
\hline \multirow[t]{6}{*}{90196} & 14DAl_1 & 49.53 & 47.15 & 7.08 & 46.55 & 94.44 & 32.67 & 69.29 \\
\hline & 14DAI_2 & 59.36 & 56.61 & 8.50 & 47.20 & 94.38 & 39.41 & 69.60 \\
\hline & 7DAI_1 & 67.26 & 61.89 & 9.28 & 46.55 & 89.89 & 43.47 & 70.24 \\
\hline & 7DAI_2 & 67.28 & 61.91 & 9.28 & 46.45 & 90.48 & 43.85 & 70.83 \\
\hline & ODAl_1 & 63.85 & 59.11 & 8.86 & 46.28 & 90.60 & 41.14 & 69.59 \\
\hline & ODAI_2 & 57.96 & 53.39 & 8.00 & 46.20 & 90.36 & 37.64 & 70.50 \\
\hline
\end{tabular}

or biogenesis, among other processes, were enriched in Profile 5 , in which gene expressions were increased at $\mathrm{T} 7$ but decreased at T14. While, just a few GO terms of biological process were notedly enriched in 90196 due to only seven DEGs from this profile. In Profile 6 of both genotypes, the overrepresented GO terms of biological process included DNA repair, response to stimulus and some other processes. The expression level of these genes peaked at $\mathrm{T} 7$ and maintained at high level during the subsequent stage. It was worth noting that we found that some DEGs in Profile 6 associated with negative regulation of response to stimulus were uniquely enriched in 90196. In the Profile 7, no DEGs of were enriched in biological process terms.

\section{Functional Annotation of DEGs at T7}

Using a cutoff of a twofold change in gene expression, a total of 2,974 up- and 239 down-regulated genes were identified in B2013 at T7, whereas 2,115 up- and 136 down-regulated genes were found in 90196 at T7. GO enrichment and KEGG pathway analysis of the up-regulated genes revealed some differences between the two genotypes. At T7, a total of 2,415 and 1,790 DEGs were assigned to all three GO categories-biological processes, cell components, and molecular functions-and 68 and $66 \mathrm{GO}$ terms (biological process) were notably enriched in B2013 and 90196, respectively $(q<0.05$; Supplementary Table S4). Strikingly, some GO terms involved in DNA repair, response to stress and microtubule-based process were enriched at T7 in B2013 $(q<0.05)$. In 90196, some DEGs were also placed in the terms of DNA repair, response to stress, among others. Besides, many helicaseencoding genes were also up-regulated both in B2013 and 90196 at T7.

\section{Functional Annotation of DEGs at T14}

At T14, a total of 2,110 up- and 1,244 down-regulated genes were identified in B2013, and a total of 2797 up- and 1069 down-regulated genes were identified in 90196. GO-term analysis of the up-regulated genes revealed that just a few terms were significantly enriched in B2013, while some enriched GO terms included organic substance metabolic process, primary metabolic process, among others, in 90196 (Supplementary Table S4). Further, down-regulated genes were subjected to 

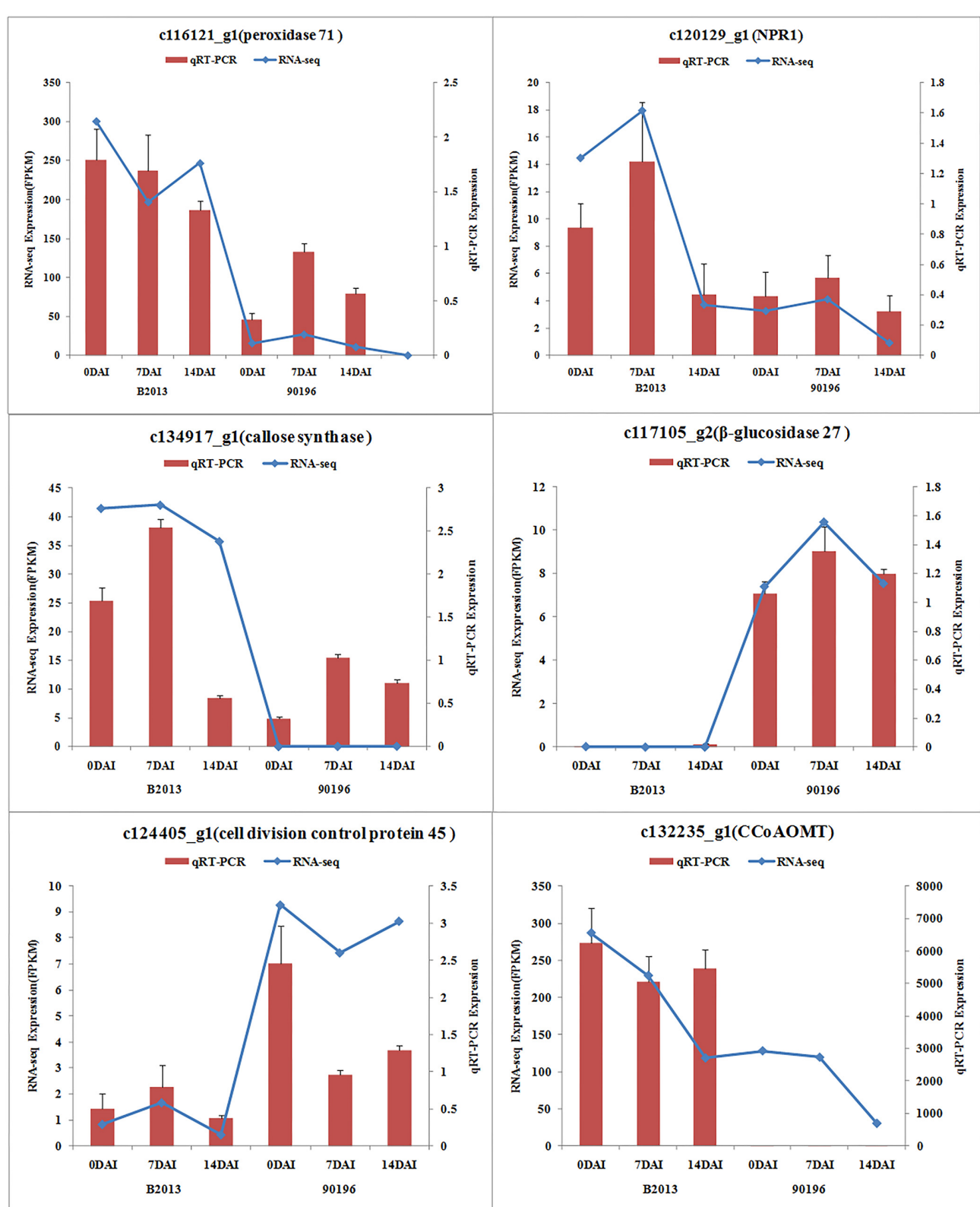

c132235_g1(CCoAOMT)
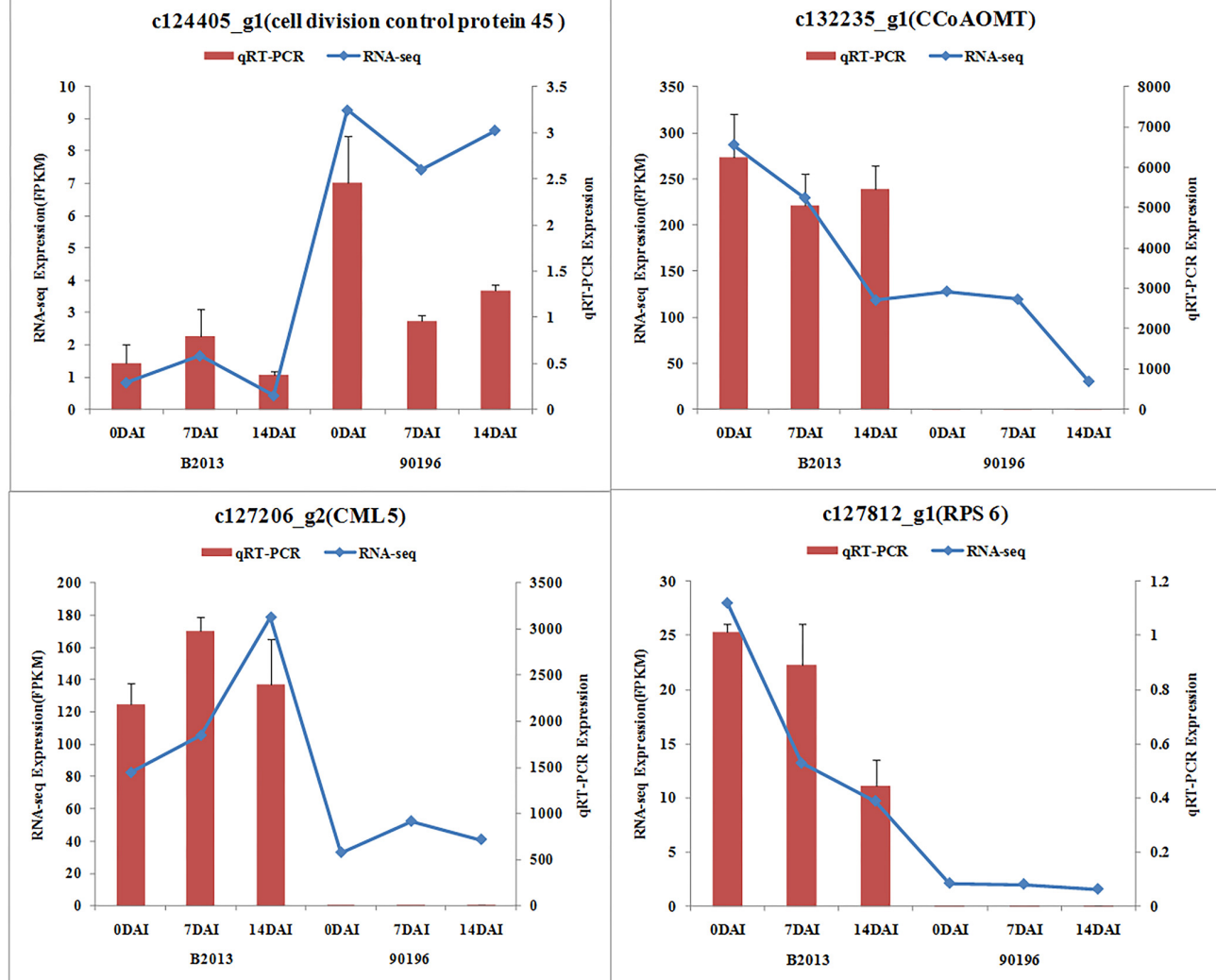

FIGURE 2 | Expression of the selected eight genes inferred by RNA -sequencing and qRT-PCR. Data from qRT-PCR are means of two replicates and bars represent SE. 

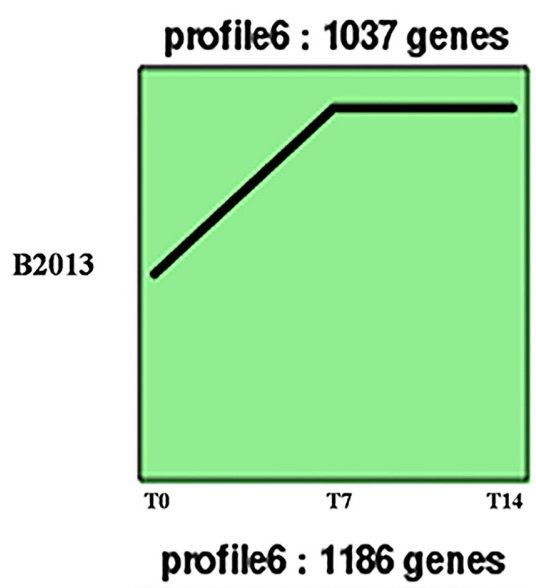

90196

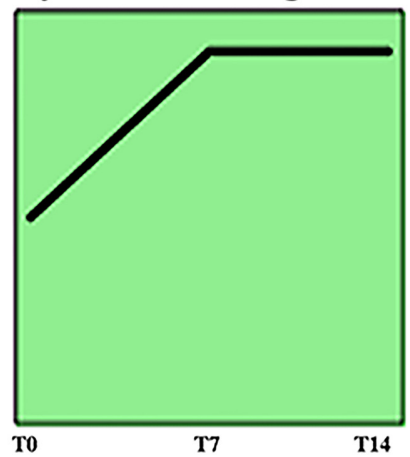

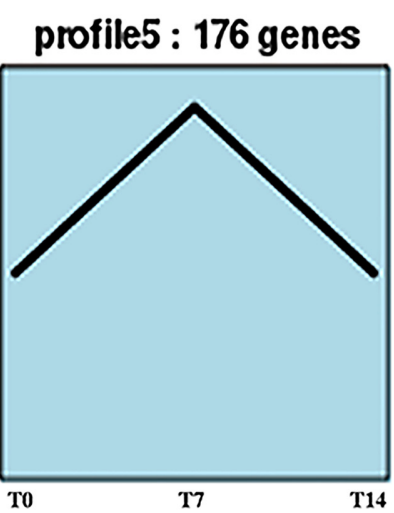

profile7 : 23 genes

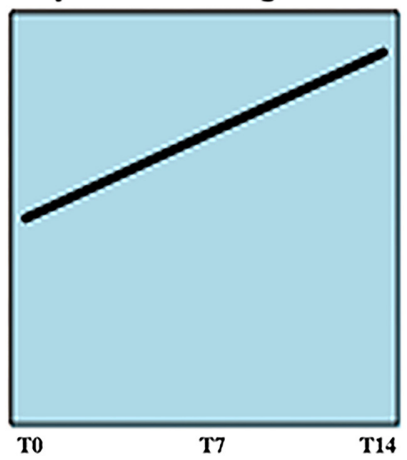

profile7 : 99 genes

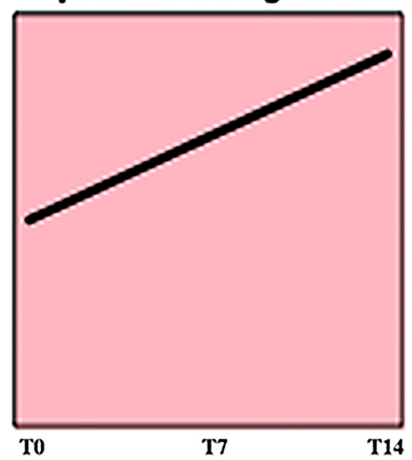

profile $5: 7$ genes

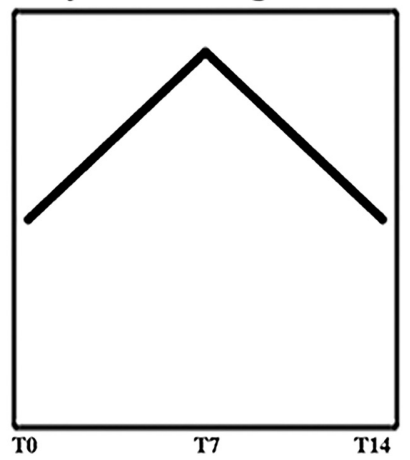

FIGURE 3 | Patterns of gene expressions across three time points in B2013 and 90196 inferred by STEM analysis (p < 0.05$)$. The black line represented the expression tendency of all the genes. The number of genes belonging to each pattern was labeled above the frame.

GO and KEGG enrichment analysis (Supplementary Tables S4 and S5). DEGs involving in the pathways of phenylpropanoid biosynthesis, plant hormone signal transduction, phenylalanine metabolism, glucosinolate biosynthesis, starch and sucrose metabolism were significantly enriched in two genotypes, which may be participated in response to $P$. brassicae infection. Detailed genes functions will be discussed below (see Defense Responses to $P$. brassicae are Induced Earlier, and Related Pathways are Repressed at T14).

\section{DEGs Involved in the Response to P. brassicae between B2013 and 90196}

To identify the genes responsible for the differences in clubroot resistance between B2013 and 90196, pairwise comparisons between the two genotypes were conducted, and 10,532, 10,051, and 6,776 DEGs were identified at T0, T7, and T14, respectively. The large number of DEGs was ascribed to the fact that genotypes from different genetic backgrounds were evaluated in the analysis. Based on these results, we chose 4,516 common DEGs for assignment in KEGG enrichment analysis, regardless of infection stage. The top 20 KEGG pathways with the highest representation of DEGs are shown in Figure 4; Table 3. Our KEGG pathway enrichment analysis of the DEGs indicated that genes related to pathogen responses were significantly enriched, including "Plant hormone signal transduction," "Plant-pathogen interaction," and others. For a global view of the DEGs involved in resistance to $P$. brassicae, the FPKM values for 64 DEGs between two genotypes were represented in a heat map (Figure 5) and Supplementary Table S6. The DEGs included seven NBS-LRR containing $R$ genes, four SA metabolism related genes, five JA metabolism related genes, eight cell wall biosynthesis or modification related genes, seven phytoalexins, six chitinase, and $17 \mathrm{Ca}^{2+}$ signaling and $\mathrm{RBOH}$ related genes. Detailed genes functions will be discussed below (see DEGs Involved in the Response to $P$. brassicae may Contribute to Genotypic Differences in Disease Symptoms).

\section{DISCUSSION}

\section{Difference in Infection Processes for Different Types of Resistance}

The clubroot disease presents a widespread and devastating damage to the plants of Brassicaceae family. To date, studies of the molecular basis of clubroot resistance from Brassica crops mainly focused on qualitative resistance, especially in Chinese cabbage (Chen et al., 2016) and canola (Chu et al., 2014). However, illuminating molecular mechanism of quantitative resistance could lead to insight into the relationship between 


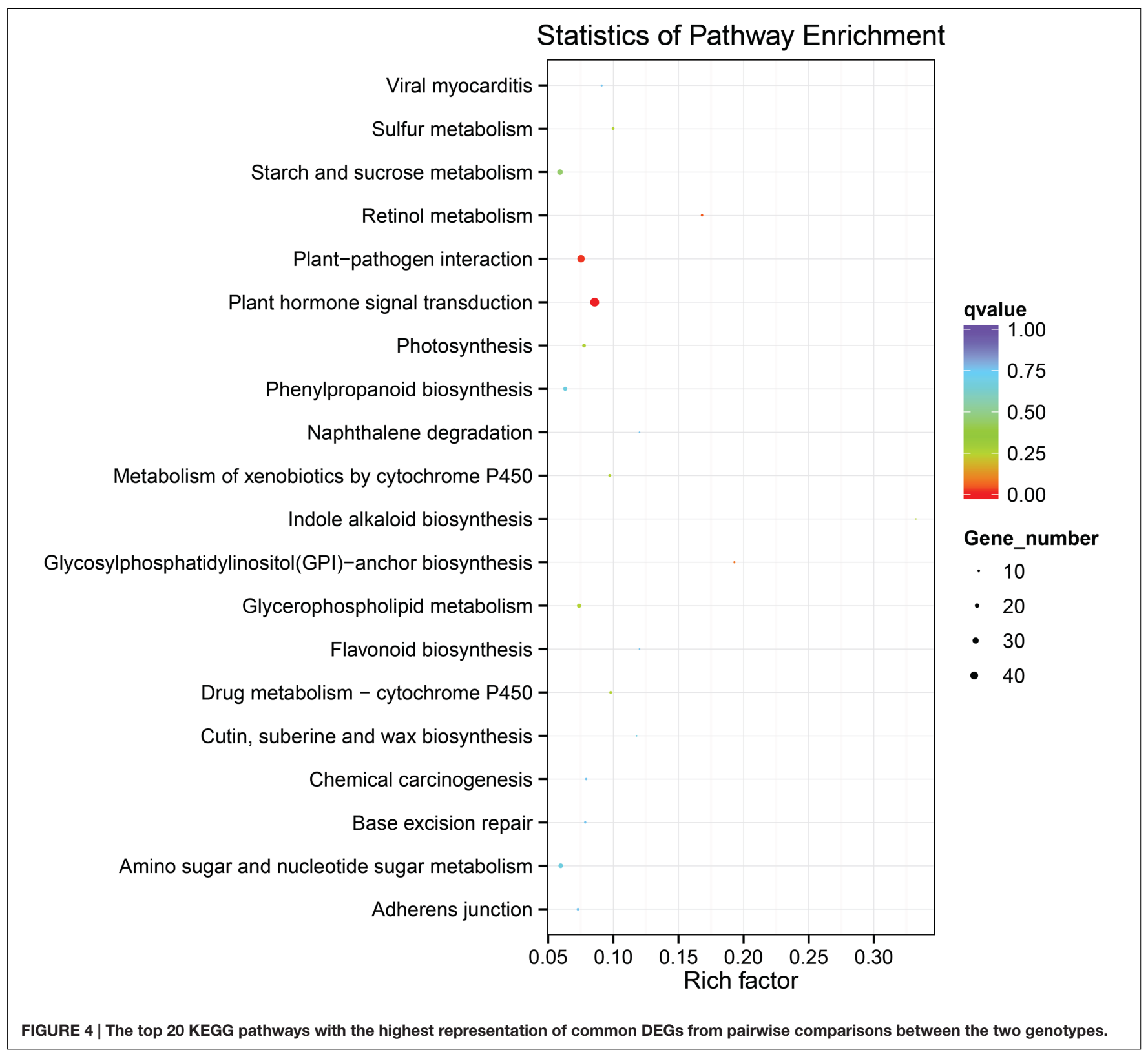

qualitative and quantitative resistance, thus to guild utilization of the two types to produce durably resistant cultivar (Jubault et al., 2013). The previous results have showed that the clubroot resistance from the wild relative B2013 was quantitative resistance controlled by multiple genes (Zhang et al., 2014). In our study, transcriptome of broccoli 90196 and its wild relative B2013 was investigated after infection with $P$. brassicae at two developmentally distinct stages. Microscopic observations revealed that root-hair infection (7 DAI) and cortical infection (14 DAI) were both present in B2013 and 90196 (Figure 1). This finding was not in agreement with previous studies (Feng et al., 2013; Chen et al., 2016), in which secondary infection did not occur in resistant lines, possibly due to qualitative resistance under single-gene control.

\section{Plant Cytoskeleton and DNA Repair Act as an Early Response to $P$. brassicae}

The plant cytoskeletons play positive roles in defense against invasion and expansion of the pathogen to plant hosts (Takemoto and Hardham, 2004). Plant-pathogen interactions result in reorganization of microtubules and microfilaments toward attempted sites of penetration, restricting pathogens primarily through the deposition of callose and antimicrobial material (Takemoto et al., 2003; Hardham et al., 2007). In current study, some DEGs associated with microtubule-based process were exclusively up-regulated during an earlier stage (T7) in B2013, yet similar transcriptional changes did not observed in 90196 at the same stage, indicating that the microtubule may participated directly in host defense response to $P$. brassicae in 
TABLE 3 | Top 20 enriched KEGG pathways with the highest representation of DEGs between B2013 and 90196.

\begin{tabular}{|c|c|c|c|}
\hline Pathway & Pathway ID & $\begin{array}{l}\text { DEGs genes with } \\
\text { pathway annotation }\end{array}$ & $\begin{array}{l}\text { Background genes with } \\
\text { pathway annotation }\end{array}$ \\
\hline Plant hormone signal transduction & ko04075 & 46 & 502 \\
\hline Retinol metabolism & ko00830 & 9 & 53 \\
\hline Glycosylphosphatidylinositol (GPI)-anchor biosynthesis & ko00563 & 7 & 36 \\
\hline Sulfur metabolism & ko00920 & 11 & 108 \\
\hline Metabolism of xenobiotics by cytochrome P450 & ko00980 & 11 & 111 \\
\hline Glycerophospholipid metabolism & ko00564 & 19 & 248 \\
\hline Photosynthesis & ko00195 & 16 & 200 \\
\hline Indole alkaloid biosynthesis & ko00901 & 3 & 9 \\
\hline Starch and sucrose metabolism & ko00500 & 27 & 430 \\
\hline Phenylpropanoid biosynthesis & ko00940 & 18 & 274 \\
\hline Flavonoid biosynthesis & ko00941 & 4 & 33 \\
\hline
\end{tabular}

resistant genotype. Besides, the genes that were involved in DNA repair participated in an early response to $P$. brassicae, due to detecting many up-regulated helicase-encoding genes both in B2013 and 90196 at T7, corroborating the findings of Zhou et al. (2016) regarding the response to Cd accumulation in Brassica chinensis.

\section{Defense Responses to $P$. brassicae Are Induced Earlier, and Related Pathways are Repressed at T14 Cell Wall Biosynthesis}

Within the phenylpropanoid biosynthesis pathway (ko00940), 24 genes associated with peroxidase (POD), participating in the biosynthesis of guaiacyl and syringyl lignin, were enriched in B2013 and 90196. Guaiacyl and syringyl are crucial components in the cell wall of angiosperm plants (Obst, 1982). Within the pentose and glucuronate interconversion pathway (ko00040), which is involved in the biosynthesis of cell wall components, eight genes encode the two key enzymes (pectinesterase and polygalacturonase) participating in D-galacturonate biosynthesis, which is essential for forming the backbone of pectic acid (Ridley et al., 2001). The results implied that cell wall biosynthesis might be suppressed by $P$. brassicae infection at T14, consistent with observations obtained from the GO enrichment analysis of expression patterns (Profile 5). Two trehalose 6phosphate synthase (TPS)-encoding genes were also downregulated in B2013 at T14, which was observed previously and proposed as a defense mechanism in A. thaliana (Gravot et al., 2011).

\section{Glucosinolate Biosynthesis}

Glucosinolates (GSLs), a group of sulfur-containing plant secondary metabolites found in the Brassicaceae family, have long been postulated to contribute to host $-P$. brassicae interactions (Ludwig-Müller et al., 2009). In the glucosinolate biosynthesis pathway, four cytochrome P450s were found to be downregulated at T14 compared with T7, among which CYP79B2 and the homolog CYP79B3 catalyze the conversion of tryptophan to indole-3-acetaldoxime (IAOx) (Mikkelsen et al., 2000), and CYP83A1 and CYP83B1 are oxime-metabolizing enzymes (Zhu et al., 2012). Previous studies have found correlations between resistance and a low indole GSL content (Butcher et al., 1974; Ockendon and Buczacki, 1979; Chong et al., 1985), whereas Mullin et al. (1980) were not able to correlate indole GSL and resistance to clubroot. In the present study, the observed downregulation of four cytochrome $\mathrm{P} 450$-encoding genes revealed low-indole GSL levels at T14, which may have contributed to the reduction of disease symptoms, although large clubs did appear in 90196.

\section{Plant Hormone Signal Transduction}

Plant hormones play pivotal signaling roles in host- $P$. brassicae interactions. In the present study, some genes involved in host auxin biosynthesis as well as auxin transport and response were found to be down-regulated at T14, and these changes occurred in both the susceptible and partially resistant responses. The down-regulation of this pathway was consistent with the reduced gall formation observed in B2013, while large clubs still appeared in 90196. Like the previous findings in B. napus, IAA-biosynthesis related genes were also induced by $P$. brassicae infection at the primary stage of the infection process (Xu et al., 2016). In addition, the SA and JA pathways were also repressed due to the down-regulation of related genes at T14. The different roles of SA and JA in defense responses between partial resistance and susceptibility to clubroot will be discussed below.

Overall, the pathways related to the defense response to $P$. brassicae were repressed at T14 in both genotypes. Additionally, most defense genes were up-regulated at T7 compared with $\mathrm{T} 14$, indicating that the defense responses to $P$. brassicae were induced quickly. 


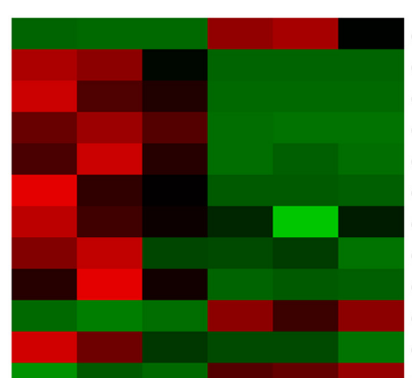

c132568_g4 RPS2 c130643_g2 RPS4 c90834_g1 RPS4 c34131_g1 RPS5 c231893 g1 RPS5 c127812_g1 RPS6 c131668 g3 TMV resistance protein $\mathrm{N}$ c120129_g1 NPR1 c120129_g2 NPR1 c136494_g3 TGA1 c132879_g2 TGA4 c129286_g2 JAZ c126290_g1 JAZ c129036_g3 JAZ c119830_g1 MYC2 c157350_g1 MYC2 c118178_g1 GAUT8 c137381_g3 GAUT8 c135534_g1 GAUT 15 c135534_g2 GAUT 15 c135534_g3 GAUT 15 c135088_g2 GAUT 6 c128699_g2 GAUT14 c130331_g1 polygalacturonase c119384_g1 peroxidase2 c117013_g1 peroxidase 55 c114152_g2 peroxidase C3 c127867_g1 peroxidase 63 c116412_g1 peroxidase 12 c116121_g1 peroxidase 71 c117105_g2 Beta-glucosidase 27 c133774_g2 Beta-glucosidase 30 c135016_g6 Beta-glucosidase 16 c137005_g7 Beta-glucosidase 3 c103068_g1 PNAE c113812 g1 STR c117496_g1 PNAE c111154_g2 FLS c126824_g2 FLS c132235_g2 CCOAOMT c132832_g1 Beta-AS c110464_g1 chitinase c121879_g2 chitinase c113983 g1 chitinase c115687_g1 chitinase c126700_g3 chitinase c16913_g1 chitinase c121365_g1 CALM c100683_g1 CML2 c127206_g2 CML5 c119197_g1 CML26 c104954_g1 CNGF12 c134539_g2 CNGF14 c104954_g2 CNGF12 c135908_g1 CPK30 c125913_g3 CPK6 c89302_g1 CPK17 c130799_g3 CPK21 c130799_g4 CPK22 c71350_g2 CPK10 c138567_g2 RBOH A c128774_g1 RBOH C c112278_g1 RBOH G c113268_g1 RBOH C

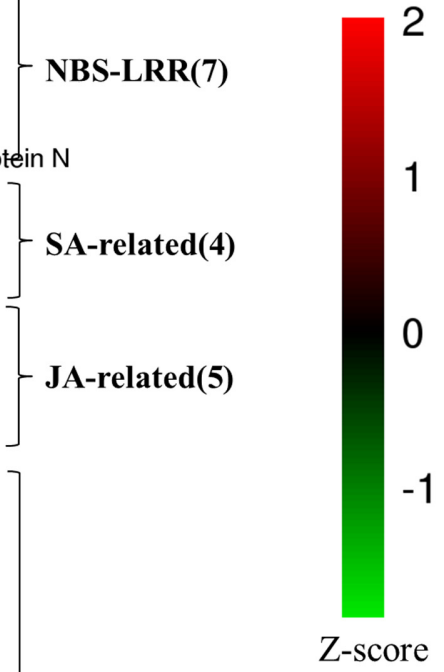

Cell wall-related(18)

Phytoalexins(7)

Chitinase(6)

$\mathrm{Ca}^{2+}$ signals and $\mathrm{RBOH}(17)$

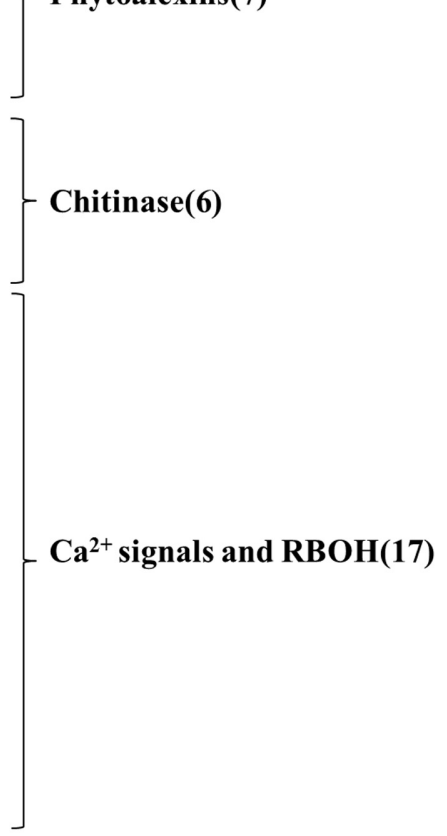

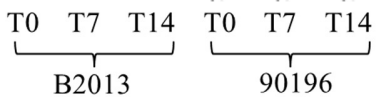

FIGURE 5 | Heatmap of common DEGs related to defense response to clubroot in B2013 and 90196. 


\section{DEGs Involved in the Response to $P$. brassicae May Contribute to Genotypic Differences in Disease Symptoms} NBS-LRR Proteins May be Involved in Resistance to P. brassicae in B2013

Plant NBS-LRR-containing $R$ genes can specifically recognize and interact with corresponding pathogen $a v r$ genes and are considered plant genetic factors that are involved in multiple layers of defense mechanisms (Yu et al., 2014). In the plant-pathogen interaction pathway, five of the six transcripts homologous to Pseudomonas syringae-resistant Arabidopsis genes were up-regulated in B2013 (one RPS2, two RPS4, twp RPS5, and one RPS6), whereas RPS 2 was not. It has been reported that RPS4, $R P S 5$, and RPS6 could be involved in resistance to $P$. syringae in A. thaliana (Ade et al., 2007; Kim et al., 2009), while RPS4 and RPS5 may be involved in the resistance interaction between $P$. brassicae and B. rapa (Chen et al., 2016). One gene encoding a TMV resistance protein was also up-regulated in B2013. The enhanced expression of $R$ genes in B2013 could represent an activation of a general "surveilance" against pathogen attempts to suppress the PTI response and trigger activation of ETI response and the subsequent defense response, which also suggested that the ETI response was more robust in resistant genotype. These $\mathrm{R}$ genes should be used as candidate genes for further investigation.

\section{The SA and JA Signal Transduction Pathways Respond Differently in Clubroot-Resistant and Clubroot-Susceptible Genotypes}

Extensive studies have shown that SA is involved in the activation of systemic acquired resistance (SAR) in plants such as A. thaliana, tobacco and rice (Durrant and Dong, 2004; Vallad and Goodman, 2004; Yuan et al., 2007). Two NPR1 homologs, identified as key regulators of SA-mediated resistance in A. thaliana, were up-regulated in B2013 after inoculation with P. brassicae, leading to the activation of downstream SA signaling. TGA factors can interact with NPR1, among which TGA1 and TGA4 are responsible for the SA-dependent interaction (Després et al., 2003). One TGA4 was up-regulated in B2013, and one TGA1 was weakly down-regulated in B2013, indicating that the TGA4-NPR1 interaction in the SA-dependent pathway may contribute to disease resistance to $P$. brassicae in B2013.

The JAZ (jasmonate-zim domain) proteins act as JA coreceptors and transcriptional repressors in JA signaling in Arabidopsis (Kazan and Manners, 2012), interacting with the positive regulator of JA signaling MYC2 (Chini et al., 2007). Thus, MYC2 inactivation results in impaired JA signaling. Two of three genes encoding JAZ proteins were up-regulated in B2013, and MYC2 was up-regulated in 90196. The results showed that the JA pathway was weakly activated in the resistant genotype but strongly induced in the susceptible genotype, in agreement with results reported for Arabidopsis by Lemarié et al. (2015). Chen et al. (2016) also demonstrated that the SA signaling pathway, but not the JA/ET signaling pathway, played a critical role in B. rapa resistance to $P$. brassicae infection. Jubault et al. (2013) also found that both the SA and ET pathways were induced during the partial resistance response, whereas the JA pathway was repressed.

\section{Enhanced Cell Wall Biosynthesis has a Link to Resistance to $P$. brassicae}

In terms of starch and sucrose metabolism, many genes involved in the biosynthesis of cell wall components exhibited different expression levels, suggesting that different cell wall-related functions were involved in response to $P$. brassicae in the two genotypes. Seven of 27 over-expressed genes within this pathway encode the key GAUT ( $\alpha$-1,4-galacturonosyltransferase) enzymes, which are essential for the biosynthesis of the plant cell wall component pectic polysaccharide homogalacturonan (HGA) (Sterling et al., 2001). With the exception of GAUT14, the other GAUT genes (one GAUT6, two GAUT8, and three GAUT15) were up-regulated in B2013 compared with 90196 at three stages. The key enzyme polygalacturonase was also elevated in B2013 at these stages. In another phenylpropanoid biosynthesis pathway, six genes associated with POD that participate in the biosynthesis of guaiacyl and syringyl lignin were up-regulated in B2013. Similar increases in lignin synthesis in roots have been observed in Cd-stressed pakchoi (Zhou et al., 2016) and Verticillium dahliaeinoculated cotton (Xu et al., 2011). This study demonstrates that lignification and reinforcement of cell walls are important processes in the response of plants to $P$. brassicae penetration.

Interestingly, three of four enzymes ( $\beta$-glucosidase) involved in the hydrolysis of cellulose were up-regulated in 90196 compared with B2013, and one was up-regulated in B2013. We inferred that host cell wall components may be degraded by hydrolytic enzymes during $P$. brassicae infection through unknown pathways, furthering the pathogen infection process. The activity of hydrolytic enzymes was higher in the susceptible genotype, resulting in a severe infection and symptoms.

\section{Phytoalexins May Contribute to Resistance toward $P$. brassicae in Resistant Genotypes}

Resistant species can also be colonized by the fungus, followed by a severe basal defense response and rapid induction of phytoalexin production. Phytoalexins are defined as "any lowmolecular-weight, anti-microbial secondary metabolites that are synthesized and accumulate in plants in response to biotic and abiotic stress" (Ahuja et al., 2012). Phytoalexins have been characterized amongst different classes of chemical compounds such as coumarins, terpenoids, flavonoid, alkaloids, stilbenes, phenolic compounds, and many others (Arruda et al., 2016). According to our pathway enrichment analysis, the indole alkaloid biosynthesis, flavonoid biosynthesis, and triterpene biosynthesis pathways exhibited more up-regulated genes in resistant lines than in susceptible lines.

Indole alkaloids are tryptophan-derived alkaloids that are important secondary metabolites and can protect plants against adverse environments, and particularly microbe invasion or insect grazing (Miranda-Ham et al., 2007). Three genes encoding the two key enzymes (two polyneuridine-aldehyde esterase [PNAE] and one strictosidine synthase [STR]) involved in indole alkaloid biosynthesis showed 2.7- to 6.3-fold higher expression in B2013 than in 90196. These genes reached their highest expression level at T14, suggesting that B2013 may have a higher indole alkaloid content, as found in aphid-resistant wheat leaves (Cai et al., 2004). 
In the current study, four genes related to flavonoid biosynthesis were identified, including two up-regulated flavonol synthase (FLS) genes and one up-regulated caffeoyl-CoA O-methyltransferase (CCoAOMT) gene. FLS, which catalyzes the reaction from dihydroflavonol to flavonol, is the key enzyme for flavonol biosynthesis (Holton et al., 1993). Flavonol plays a role as a UV protectant (Flint et al., 1985) and in scavenging ROS ( $\mathrm{Vu}$ et al., 2015). In A. thaliana, transcripts of selected genes involved in each step of flavonoid biosynthesis are up-regulated during clubroot development (Ludwig-Müller et al., 2009). CCoAOMT activity in cultured carrot cells was found to be rapidly induced in response to fungal elicitors (Kühnl et al., 1989). Recently, CCoAOMT has been shown to participate in lignin biosynthesis in woody poplar (Zhong et al., 2000), and down-regulation of CCOAOMT via RNA interference leads to reduced lignin production in the cell wall of maize straw (Li et al., 2013). We deduced that up-regulation of CCOAOMT may lead to an increased lignin content, thickening the cell wall of the host and reducing root tissue damage due to $P$. brassicae infection in B2013.

Triterpenes, a major subgroup of the terpene superfamily, are valuable metabolites with antiviral and antibacterial properties (Alakurtti et al., 2006) that are derived from the cyclization of 2, 3-oxidosqualene by oxidosqualene cyclases (OSCs) (Delis et al., 2011). The $\beta$-AS ( $\beta$-amyrin synthase) gene, encoded by OSC3, has been shown to be required for the synthesis of defense compounds (Haralampidis et al., 2001). In the present study, one $\beta$-AS-related gene was found to be up-regulated in B2013 compared to 90196 .

In summary, phytoalexins including indole alkaloids, indole alkaloids, and triterpenes were shown to act as defense compounds against $P$. brassicae. Seven genes responsible for the biosynthesis of different types of phytoalexins were markedly up-regulated in B2013 at various stages compared with 90196 and were therefore thought to likely contribute to resistance to $P$. brassicae in resistant genotype. However, few genes involved in phytoalexins biosynthesis were found to be differentially expressed between different resistance in Arabidopsis (Jubault et al., 2013).

\section{Chitinase Responds Differently to $P$. brassicae Infection in Resistant and Susceptible Genotypes}

We identified six chitinase genes that were differentially expressed between the two genotypes, among which four were up-regulated in B2013. Chitinases catalyze the hydrolysis of chitin, a major component of the cell walls of $P$. brassicae (Moxham and Buczacki, 1983), and are a type of pathogenesisrelated (PR)-like protein that has been used to trigger defense responses against fungal pathogens (Xian et al., 2012). There is still no direct evidence demonstrating that chitin released by $P$. brassicae is $\mathrm{PR}$, although several chitin synthases are highly expressed in $P$. brassicae during infection (Schwelm et al., 2015). Four up-regulated genes showed 1.7- to 8.9-fold higher expression in B2013 than in 90196, reaching the highest expression level at T14, revealing that the activity of chitinase increased gradually as infection progressed, while two downregulated genes reached their highest expression level at T0 (c110464_g1) or T14 (c121879_g2). These results showed that different chitinases played distinct roles at different infection stages, as observed in B. rapa by Chen et al. (2016). The chitinase genes that showed higher expression levels during secondary infection appeared to likely be more conducive to triggering host defenses against $P$. brassicae in the current study.

\section{$\mathrm{Ca}^{2+}$ Signaling may be Involved in the Response to P. brassicae Infection by Activating RBOH Proteins}

Genes related to $\mathrm{Ca}^{2+}$ influx have been suggested to play a key role in the genotypic differences underlying clubroot resistance (Chen et al., 2016). Changes in cytosolic $\mathrm{Ca}^{2+}$ levels are a primary response to biotic and abiotic stress (Rudd and Franklin-Tong, 2001). Three genes (two CNGC12, one CNGC 14) encoding cyclic nucleotide gated channels (CNGCs) were markedly up-regulated in B2013 compared with 90196 at three stages. CNGCs are a group of cation channels that mediate $\mathrm{Ca}^{2+}$ influx into the cytosol following activation via ligand binding (Jammes et al., 2011). They play important roles in the response to signals from pathogens and pathogen-associated molecular pattern (PAMP) signals (Ma, 2011). Calmodulins (CaMs) and calmodulin-like proteins (CMLs) are also involved in the pathogen response signaling cascade, functioning as $\mathrm{Ca}^{2+}$ sensors (Ma, 2011). The genes related to CaM, CML2, CML5, and CML26 were all up-regulated in B2013 compared with 90196. In addition, four of six calcium-dependent protein kinase $(\mathrm{CPK})$ genes $(\mathrm{CPK} 10,17,21,22)$ were also up-regulated in B2013 at three time points. $C P K$, a family of serine/threonine protein kinases that are unique to plants and some protists, may be involved in multiple signal transduction pathways (Martín and Busconi, 2001). Moreover, $\mathrm{Ca}^{2+}$ signals can activate respiratory burst oxidase homolog $(\mathrm{RBOH})$ proteins, which are involved in mediating the production of reactive oxygen species (ROS) (Kurusu et al., 2015). As expected, four RBOHrelated genes (one $R B O H A$, two $R B O H C$, one $R B O H G$ ) were up-regulated in B2013, indicating that a higher ROS level in the resistant genotype contributed to inhibition of colonization by $P$. brassicae in the roots, in agreement with previous findings in B. rapa after infection by $P$. brassicae (Chen et al., 2016).

\section{CONCLUSION}

We first investigated the transcriptome response in the roots of clubroot -susceptible broccoli line and its clubroot-resistant wild relative line during the different stages of $P$. brassicae infection. In our study, two findings that (1) the response changes in transcript level of two genotypes under $P$. brassicae infection were mainly activated at the primary stage (T7). Some pathways related to cell wall and glucosinolate biosynthesis and plant hormone signal transduction were repressed at T14(the secondary stage) compared to T7, and (2) the pathways associated with response defense to clubroot were activated in the resistant genotype. Our results could provide new insights into the molecular mechanisms underlying the resistance to $P$. brassicae. 


\section{AUTHOR CONTRIBUTIONS}

$\mathrm{XZ}$ performed the experiments, analyzed the data, wrote and revised the manuscript; YL designed the research and critically edited the manuscript; ZF guided the experimental design; ZL and LY performed the data analysis; and MZ, YZ, and HL planted and managed the plants. All authors approved the final manuscript.

\section{ACKNOWLEDGMENTS}

This work was funded by the Key Projects in the National Science and Technology Pillar Program of China (grant no. 2013BAD01B04), the China Agriculture Research System (grant no. CARS-25-A), the National Natural Science Foundation of

\section{REFERENCES}

Ade, J., Deyoung, B. J., Golstein, C., and Innes, R. W. (2007). Indirect activation of a plant nucleotide binding site-leucine-rich repeat protein by a bacterial protease. Proc. Natl. Acad. Sci. U.S.A. 104, 2531-2536. doi: 10.1073/pnas.0608779104

Agarwal, A., Kaul, V., Faggian, R., Rookes, J. E., Ludwig-Müller, J., and Cahill, D. M. (2011). Analysis of global host gene expression during the primary phase of the Arabidopsis thaliana-Plasmodiophora brassicae interaction. Funct. Plant Biol. 38, 462-478. doi: 10.1071/FP11026

Ahuja, I., Kissen, R., and Bones, A. M. (2012). Phytoalexins in defense against pathogens. Trends Plant Sci. 17, 73-90. doi: 10.1016/j.tplants.2011.11.002

Alakurtti, S., Mäkelä, T., Koskimies, S., and Yli-Kauhaluoma, J. (2006). Pharmacological properties of the ubiquitous natural product betulin. Eur. J. Pharm. Sci. 29, 1-13. doi: 10.1016/j.ejps.2006.04.006

Alix, K., Lariagon, C., Delourme, R., and Manzanares-Dauleux, M. J. (2007). Exploiting natural genetic diversity and mutant resources of Arabidopsis thaliana to study the A. thaliana-Plasmodiophora brassicae interaction. Plant Breed. 126, 218-221. doi: 10.1111/j.1439-0523.2007.01314.x

Anders, S., and Huber, W. (2010). Differential expression analysis for sequence count data. Genome Biol. 11:R106. doi: 10.1186/gb-2010-11-10-r106

Arruda, R. L., Paz, A. T. S., Bara, M. T. F., Côrtes, M. V. D. C. B., Filippi, M. C. C. D., and Conceição, E. C. D. (2016). An approach on phytoalexins: function, characterization and biosynthesis in plants of the family Poaceae. Cienc. Rural 46, 1206-1216. doi: 10.1590/0103-8478cr20151164

Benjamini, Y., and Hochberg, Y. (1995). Controlling the false discovery ratea practical and powerful approach to multiple testing. J. R. Stat. Soc. 57, 289-300.

Butcher, D. N., El-Tigani, S., and Ingram, D. S. (1974). The role of indole glucosinolates in the club root disease of the Cruciferae. Physiol. Plant Pathol. 4, 127-140. doi: 10.1016/0048-4059(74)90052-6

Cai, Q. N., Zhang, Q. W., and Cheo, M. (2004). Contribution of indole alkaloids to Sitobion avenae (F.) resistance in wheat. J. Appl. Entomol. 128, 517-521. doi: 10.1111/j.1439-0418.2004.00770.x

Chen, J., Pang, W., Chen, B., Zhang, C., and Piao, Z. (2016). Transcriptome analysis of Brassica rapa near-isogenic lines carrying clubroot-resistant and-susceptible alleles in response to Plasmodiophora brassicae during early infection. Front. Plant Sci. 6:1183. doi: 10.3389/fpls.2015.01183

Chini, A., Fonseca, S., Fernández, G., Adie, B., Chico, J. M., Lorenzo, O., et al. (2007). The JAZ family of repressors is the missing link in jasmonate signaling. Nature 448, 666-671. doi: 10.1038/nature06006

Chong, C., Chiang, M. S., and Crete, R. (1985). Studies on glucosinolates in clubroot resistant selections and susceptible commercial cultivars of cabbages. Euphytica 34, 65-73. doi: 10.1007/BF00022864

Chu, M., Song, T., Falk, K. C., Zhang, X., Liu, X., Chang, A., et al. (2014). Fine mapping of Rcr1 and analyses of its effect on transcriptome patterns during infection by Plasmodiophora brassicae. BMC Genomics 15:1166. doi: 10.1186/ 1471-2164-15-1166
China (grant no. 31372067), the Key Laboratory of Biology and Genetic Improvement of Horticultural Crops, Ministry of Agriculture, China. We also acknowledge partial funding from the Science and Technology Innovation Program of the Chinese Academy of Agricultural Sciences (grant no. CAAS-ASTIPIVFCAAS).

\section{SUPPLEMENTARY MATERIAL}

The Supplementary Material for this article can be found online at: http://journal.frontiersin.org/article/10.3389/fpls.2016.01929/ full\#supplementary-material

FIGURE S1 | Disease symptoms of 90196 (A) and B2013 (B) 42 day after $P$. brassicae inoculation.

Conesa, A., Götz, S., García-Gómez, J. M., Terol, J., Talón, M., and Robles, M. (2005). Blast2GO: a universal tool for annotation, visualization and analysis in functional genomics research. Bioinformatics 21, 3674-3676. doi: 10.1093/ bioinformatics/bti610

Deckers, P. (2006). A hormone and proteome approach to picturing the initial metabolic events during Plasmodiophora brassicae infection on Arabidopsis. Mol. Plant Microbe Interact. 19, 1431-1443. doi: 10.1094/MPMI-19-1431

Delis, C., Krokida, A., Georgiou, S., Peña-Rodríguez, L. M., Kavroulakis, N., Ioannou, E., et al. (2011). Role of lupeol synthase in Lotus japonicus nodule formation. New Phytol. 189, 335-346. doi: 10.1111/j.1469-8137.2010.03463.x

Després, C., Chubak, C., Rochon, A., Clark, R., Bethune, T., Desveaux, D., et al. (2003). The Arabidopsis NPR1 disease resistance protein is a novel cofactor that confers redox regulation of DNA binding activity to the basic domain/leucine zipper transcription factor TGA1. Plant Cell 15, 2181-2191. doi: 10.1105/tpc. 012849

Diederichsen, E., Frauen, M., Linders, E. G. A., Hatakeyama, K., and Hirai, M. (2009). Status and perspectives of Clubroot resistance breeding in crucifer crops. J. Plant Growth Regul. 28, 265-281. doi: 10.1007/s00344-009-9100-0

Dixon, G. R. (2009). The occurrence and economic impact of Plasmodiophora brassicae and clubroot disease. J. Plant Growth Regul. 28, 194-202. doi: 10.1007/ s00344-009-9090-y

Durrant, W. E., and Dong, X. (2004). Systemic acquired resistance. Annu. Rev. Phytopathol. 42, 185-209. doi: 10.1146/annurev.phyto.42.040803.14042

Feng, J., Hwang, S. F., and Strelkov, S. E. (2013). Studies into primary and secondary infection processes by Plasmodiophora brassicae on canola. Plant Pathol. 62, 177-183. doi: 10.1111/j.1365-3059.2012.02612.x

Flint, S. D., Jordan, P. W., and Caldwell, M. M. (1985). Plant protective response to enhanced UV-B radiation under field conditions: leaf optical properties and photosynthesis. Photochem. Photobiol. 41, 95-99. doi: 10.1111/j.1751-1097. 1985.tb03454.x

Fuchs, H., and Sacristan, M. D. (1996). Identification of a gene in Arabidopsis thaliana controlling resistance to clubroot (Plasmodiophora brassicae) and characterisation of the resistance response. Mol. Plant Microbe Interact. 9, 91-97. doi: 10.1094/MPMI-9-0091

Gómez-Lobato, M. E., Hasperué, J. H., Civello, P. M., Chaves, A. R., and Martínez, G. A. (2012). Effect of 1-MCP on the expression of chlorophyll degrading genes during senescence of broccoli (Brassica oleracea L.). Sci. Hortic. 144, 208-211. doi: 10.1016/j.scienta.2012.07.017

Grabherr, M. G., Haas, B. J., Yassour, M., Levin, J. Z., Thompson, D. A., Amit, I., et al. (2011). Full-length transcriptome assembly from RNA-Seq data without a reference genome. Nat. Biotechnol. 29, 644-652. doi: 10.1038/nbt.1883

Gravot, A., Grillet, L., Wagner, G., Jubault, M., Lariagon, C., Baron, C., et al. (2011). Genetic and physiological analysis of the relationship between partial resistance to clubroot and tolerance to trehalose in Arabidopsis thaliana. New Phytol. 19, 1083-1094. doi: 10.1111/j.1469-8137.2011.03751.x

Haralampidis, K., Bryan, G., Qi, X., Papadopoulou, K., Bakht, S., and Melton, R. (2001). A new class of oxidosqualene cyclases directs synthesis of antimicrobial 
phytoprotectants in monocots. Proc. Natl. Acad. Sci. U.S.A. 98, 13431-13436. doi: 10.1073/pnas.231324698

Hardham, A. R., Jones, D. A., and Takemoto, D. (2007). Cytoskeleton and cell wall function in penetration resistance. Curr. Opin. Plant Biol. 10, 342-348. doi: 10.1016/j.pbi.2007.05.001

Hoagland, D. R., and Arnon, D. I. (1950). The water-culture method for growing plants without soil. Circ. Calif. Agric. Exp. Stn. 347, 357-359.

Holton, T. A., Brugliera, F., and Tanaka, Y. (1993). Cloning and expression of flavonol synthase from Petunia hybrid. Plant J. 4, 1003-1010. doi: 10.1046/j. 1365-313X.1993.04061003.x

Jammes, F., Hu, H. C., Villiers, F., Bouten, R., and Kwak, J. M. (2011). Calciumpermeable channels in plant cells. FEBS J. 278, 4262-4276. doi: 10.1111/j.17424658.2011.08369.x

Jubault, M., Hamon, C., Gravot, A., Lariagon, C., Delourme, R., Bouchereau, A., et al. (2008a). Differential regulation of root arginine catabolism and polyamine metabolism in clubroot-susceptible and partially resistant Arabidopsis genotypes. Plant Physiol. 146, 2008-2019. doi: 10.1104/pp.108. 117432

Jubault, M., Lariagon, C., Simon, M., Delourme, R., and Manzanares-Dauleux, M. J. (2008b). Identification of quantitative trait loci controlling partial clubroot resistance in new mapping populations of Arabidopsis thaliana. Theor. Appl. Genet. 117, 191-202. doi: 10.1007/s00122-008-0765-8

Jubault, M., Lariagon, C., Taconnat, L., Renou, J. P., Gravot, A., Delourme, R., et al. (2013). Partial resistance to clubroot in Arabidopsis is based on changes in the host primary metabolism and targeted cell division and expansion capacity. Funct. Integr. Genomics 13, 191-205. doi: 10.1007/s10142-013-0312-9

Kageyama, K., and Asano, T. (2009). Life cycle of Plasmodiophora brassicae. J. Plant Growth Regul. 28, 203-211. doi: 10.1007/s00344-009-9101-z

Kazan, K., and Manners, J. M. (2012). JAZ repressors and the orchestration of phytohormone crosstalk. Trends Plant Sci. 17, 22-31. doi: 10.1016/j.tplants. 2011.10.006

Kim, S. H., Kwon, S. I., Saha, D., Anyanwu, N. C., and Gassmann, W. (2009). Resistance to the Pseudomonas syringae effector HopAl is governed by the TIRNBS-LRR protein RPS6 and is enhanced by mutations in SRFR1. Plant Physiol. 150, 1723-1732. doi: 10.1104/pp.109.139238

Kobelt, P., Siemens, J., and Sacristán, M. D. (2000). Histological characterisation of the incompatible interaction between Arabidopsis thaliana and the obligate biotrophic pathogen Plasmodiophora brassicae. Mycol. Res. 104, 220-225. doi: 10.1017/S0953756299001781

Koch, E., Cox, R., and Williams, P. H. (1991). Infection of Arabidopsis thaliana by Plasmodiophora brassicae. J. Phytopathol. 132, 99-104. doi: 10.1111/j.14390434.1991.tb00100.x

Kühnl, T., Koch, U., Heller, W., and Wellmann, E. (1989). Elicitor induced S-adenosyl-1-methionine: caffeoyl-CoA 3-O-methyltransferase from carrot cell suspension cultures. Plant Sci. 60, 21-25. doi: 10.1016/0168-9452(89)90039-3

Kurusu, T., Kuchitsu, K., and Tada, Y. (2015). Plant signaling networks involving $\mathrm{Ca} 2+$ and Rboh/Nox-mediated ROS production under salinity stress. Front. Plant Sci. 6:427. doi: 10.3389/fpls.2015.00427

Lemarié, S., Robert-Seilaniantz, A., Lariagon, C., Lemoine, J., Marnet, N., Jubault, M., et al. (2015). Both the jasmonic acid and the salicylic acid pathways contribute to resistance to the biotrophic clubroot agent Plasmodiophora brassicae in Arabidopsis. Plant Cell Physiol. 56, 2158-2168. doi: 10.1093/pcp/ pcv127

Li, B., Dewey, C. N., Li, B., and Dewey, C. N. (2011). RSEM: accurate transcript quantification from RNA-Seq data with or without a reference genome. BMC Bioinformatics 12:323. doi: 10.1186/1471-2105-12-323

Li, X., Chen, W., Zhao, Y., Xiang, Y., Jiang, H., Zhu, S., et al. (2013). Downregulation of caffeoyl-CoA O-methyltransferase (CCoAOMT) by RNA interference leads to reduced lignin production in maize straw. Genet. Mol. Biol. 36, 540-546. doi: 10.1590/S1415-47572013005000039

Livak, K. J., and Schmittgen, T. D. (2001). Analysis of relative gene expression data using real-time quantitative PCR and the 2- $\Delta \Delta$ CT method. Methods 25, 402-408. doi: 10.1006/meth.2001.1262

Ludwig-Müller, J., Prinsen, E., Rolfe, S. A., and Scholes, J. D. (2009). Metabolism and plant hormone action during clubroot disease. J. Plant Growth Regul. 28, 229-244. doi: 10.1103/PhysRevB.56.12608

Luo, H., Chen, G., Liu, C., Huang, Y., and Xiao, C. (2014). An improved culture solution technique for Plasmodiophora brassicae infection and the dynamic infection in the root hair. Australas. Plant Pathol. 43, 53-60. doi: 10.1007/ s13313-013-0240-0

$\mathrm{Ma}, \mathrm{W} .(2011)$. Roles of $\mathrm{Ca} 2+$ and cyclic nucleotide gated channel in plant innate immunity. Plant Sci. 181, 342-346. doi: 10.1016/j.plantsci.2011.06.002

Manzanares-Dauleux, M. J., Divaret, I., Baron, F., and Thomas, G. (2000). Evaluation of French Brassica oleracea, landraces for resistance to Plasmodiophora brassicae. Euphytica 113, 211-218. doi: 10.1023/A: 1003997421340

Martín, M. L., and Busconi, L. (2001). A rice membrane-bound calcium-dependent protein kinase is activated in response to low temperature. Plant Physiol. 125, 1442-1449. doi: 10.1104/pp.125.3.1442

Mikkelsen, M. D., Hansen, C. H., Wittstock, U., and Halkier, B. A. (2000). Cytochrome P450 CYP79B2 from Arabidopsis catalyzes the conversion of tryptophan to indole-3-acetaldoxime, a precursor of indole glucosinolates and indole-3-acetic acid. J. Biol. Chem. 275, 33712-33717. doi: 10.1074/jbc. M001667200

Miranda-Ham, M. D. L., Islas-Flores, I., and Vázquez-Flota, A. F. (2007). Accumulation of monoterpenoid indole alkaloids in periwinkle seedlings ( Catharanthus roseus ) as a model for the study of plant-environment interactions. Biochem. Mol. Biol. Educ. 35, 206-210. doi: 10.1002/bmb.60

Mithen, R., and Magrath, R. (1992). A contribution to the life history of Plasmodiophora brassicae: secondary plasmodia development in root galls of Arabidopsis thaliana. Mycol. Res. 96, 877-885. doi: 10.1016/S0953-7562(09) 81035-6

Moxham, S. E., and Buczacki, S. T. (1983). Chemical composition of the resting spore wall of Plasmodiophora brassicae. Trans. Br. Mycol. Soc. 80, 297-304. doi: 10.1016/S0007-1536(83)80013-8

Mullin, W. J., Proudfoot, K. G., and Collins, M. J. (1980). Glucosinolate content and clubroot of rutabaga and turnip. Can. J. Plant Sci. 60, 605-612. doi: 10. 4141/cjps80-087

Obst, J. R. (1982). Guaiacyl and syringyl lignin composition in hardwood cell components. Holzforschung 36, 143-152. doi: 10.1515/hfsg.1982.36.3.143

Ockendon, J. G., and Buczacki, S. T. (1979). Indole glucosinolate incidence and clubroot susceptibility of three cruciferous weeds. Trans. Br. Mycol. Soc. 72, 156-157. doi: 10.1016/S0007-1536(79)80020-0

Ridley, B. L., O’Neill, M. A., and Mohnen, D. (2001). Pectins: structure, biosynthesis, and oligogalacturonide-related signaling. Phytochemistry 57, 929-967. doi: 10.1016/S0031-9422(01)00113-3

Rolfe, S. A., Strelkov, S. E., Links, M. G., Clarke, W. E., Robinson, S. J., Djavaheri, M., et al. (2016). The compact genome of the plant pathogen Plasmodiophora brassicae, is adapted to intracellular interactions with host Brassica spp. BMC Genomics 17:272. doi: 10.1186/s12864-016-2597-2

Rudd, J. J., and Franklin-Tong, V. E. (2001). Unravelling response-specificity in Ca2+ signalling pathways in plant cells. New Phytol. 151, 7-33. doi: 10.1046/j. 1469-8137.2001.00173.x

Schuller, A., Kehr, J., and Ludwig-müller, J. (2014). Laser microdissection coupled to transcriptional profiling of arabidopsis roots inoculated by Plasmodiophora brassicae indicates a role for brassinosteroids in clubroot formation. Plant Cell Physiol. 55, 392-411. doi: 10.1093/pcp/pct174

Schwelm, A., Fogelqvist, J., Knaust, A. A., Jülke, S., Lilja, T., Bonilla-Rosso, G., et al. (2015). The Plasmodiophora brassicae genome reveals insights in its lifecycle and ancestry of chitin synthases. Sci. Rep. 5:11153. doi: 10.1038/srep11153

Siemens, J., Glawischnig, E., and Ludwig-Müller, J. (2008). Indole glucosinolates and camalexin do not influence the development of the clubroot disease in Arabidopsis thaliana. J. Phytopathol. 156, 332-337. doi: 10.1111/j.1439-0434. 2007.01359.x

Siemens, J., Keller, I., Sarx, J., Kunz, S., Schuller, A., Nagel, W., et al. (2006). Transcriptome analysis of Arabidopsis clubroots indicate a key role for cytokinins in disease development. Mol. Plant Microbe Interact. 19, 480-494. doi: 10.1094/MPMI-19-0480

Siemens, J., Nagel, M., Ludwig-Müller, J., and Sacristán, M. D. (2002). The interaction of Plasmodiophora brassicae and Arabidopsis thaliana: parameters for disease quantification and screening of mutant lines. J. Phytopathol. 150, 592-605. doi: 10.1046/j.1439-0434.2002.00818.x

Sterling, J. D., Quigley, H. F., Orellana, A., and Mohnen, D. (2001). The catalytic site of the pectin biosynthetic enzyme alpha-1, 4-galacturonosyltransferase is located in the lumen of the Golgi. Plant Physiol. 127, 360-371. doi: 10.1104/pp. 127.1.360 
Takemoto, D., and Hardham, A. R. (2004). The cytoskeleton as a regulator and target of biotic interactions in plants. Plant Physiol. 136, 3864-3876. doi: 10. 1104/pp.104.052159

Takemoto, D., Jones, D. A., and Hardham, A. R. (2003). GFP-tagging of cell components reveals the dynamics of subcellular re-organization in response to infection of Arabidopsis by oomycete pathogens. Plant J. 33, 775-792. doi: 10.1046/j.1365-313X.2003.01673.x

Tomita, H., Shimizu, M., Doullah, A. U., and Fujimoto, R. (2013). Accumulation of quantitative trait loci conferring broad-spectrum clubroot resistance in Brassica oleracea. Mol. Breed. 32, 889-900. doi: 10.1007/s11032-013-9918-9

Trapnell, C., Williams, B. A., Pertea, G., Mortazavi, A., Kwan, G., van Baren, M. J., et al. (2010). Transcript assembly and quantification by RNA-Seq reveals unannotated transcripts and isoform switching during cell differentiation. Nat. Biotechnol 28, 511-515. doi: 10.1038/nbt.1621

Vallad, G. E., and Goodman, R. M. (2004). Systemic acquired resistance and induced systemic resistance in conventional agriculture. Crop Sci. 44, 1920-1934. doi: 10.2135/cropsci2004.1920

Vu, T. T., Jeong, C. Y., Nguyen, H. N., Lee, D., Lee, S. A., Kim, J. H., et al. (2015). Characterization of Brassica napus flavonol synthase involved in flavonol biosynthesis in Brassica napus L. J. Agric. Food Chem. 63, 7819-7829. doi: 10.1021/acs.jafc.5b02994

Williams, P. H. (1966). A system for the determination of races of Plasmodiophora brassicae that infect cabbage and rutabaga. Phytopathology 56, 624-626.

Xian, H., Li, J., Zhang, L., and Li, D. (2012). Cloning and functional analysis of a novel chitinase gene Trchil from Trichothecium roseum. Biotechnol. Lett. 34, 1921-1928. doi: 10.1007/s10529-012-1020-6

Xu, L., Ren, L., Chen, K., Liu, F., and Fang, X. (2016). Putative role of IAA during the early response of Brassica napus L. to Plasmodiophora brassicae. Eur. J. Plant Pathol. 145, 1-13. doi: 10.1007/s10658-016-0877-y

Xu, L., Zhu, L., Tu, L., Liu, L., Yuan, D., Jin, L., et al. (2011). Lignin metabolism has a central role in the resistance of cotton to the wilt fungus Verticillium dahliae as revealed by RNA-Seq-dependent transcriptional analysis and histochemistry. J. Exp. Bot. 62, 5607-5621. doi: 10.1093/jxb/err245

Yu, J., Tehrim, S., Zhang, F., Tong, C., Huang, J., Cheng, X., et al. (2014). Genomewide comparative analysis of NBS-encoding genes between Brassica species and Arabidopsis thaliana. BMC Genomics 15:3. doi: 10.1186/1471-2164-15-3
Yuan, Y., Zhong, S., Li, Q., Zhu, Z., Lou, Y., Wang, L., et al. (2007). Functional analysis of rice NPR1-like genes reveals that OsNPR1/NH1 is the rice orthologue conferring disease resistance with enhanced herbivore susceptibility. Plant Biotechnol. J. 5, 313-324. doi: 10.1111/j.1467-7652.2007. 00243.x

Zhang, X. (2014). Genetic Analysis and Created Germplasm of Clubroot Resistance in Broccoli (Brassica oleracea L. var. Italica) [Master's Thesis]. Beijing: Chinese Academy of Agricultural Sciences.

Zhang, X., Li, Z., Fang, Z., Li, B., Chai, A., Sun, J., et al. (2014). Genetic analysis of clubroot resistance in the populations of broccoli $\times$ wild cabbage accession B2013'. Acta Hortic. Sin. 41, 2225-2230.

Zhong, R., Morrison, W. H., Himmelsbach, D. S., Poole, F. L., and Ye, Z. H. (2000). Essential role of caffeoyl coenzyme A O-methyltransferase in lignin biosynthesis in woody poplar plants. Plant Physiol. 124, 563-578. doi: 10.1104/pp.124. 2.563

Zhou, Q., Guo, J. J., He, C. T., Shen, C., Huang, Y. Y., Chen, J. X., et al. (2016). Comparative transcriptome analysis between low- and high-cadmiumaccumulating genotypes of pakchoi (Brassica chinensis L.) in response to cadmium stress. Environ. Sci. Technol. 50, 6485-6494. doi: 10.1021/acs.est. 5 b06326

Zhu, B., Wang, Z., Yang, J., Zhu, Z., and Wang, H. (2012). Isolation and expression of glucosinolate synthesis genes CYP83A1 and CYP83B1 in pak choi (Brassica rapa L. ssp. chinensis var. communis (N. Tsen \& S.H. Lee) Hanelt). Int. J. Mol. Sci. 13, 5832-5843. doi: 10.3390/ijms13055832

Conflict of Interest Statement: The authors declare that the research was conducted in the absence of any commercial or financial relationships that could be construed as a potential conflict of interest.

Copyright (c) 2016 Zhang, Liu, Fang, Li, Yang, Zhuang, Zhang and Lv. This is an open-access article distributed under the terms of the Creative Commons Attribution License (CC BY). The use, distribution or reproduction in other forums is permitted, provided the original author(s) or licensor are credited and that the original publication in this journal is cited, in accordance with accepted academic practice. No use, distribution or reproduction is permitted which does not comply with these terms. 